\title{
Superstructure-Based MINLP Formulation for Synthesis of Semicontinuous Mass Exchanger Networks
}

\author{
Cheng-Liang Chen* and Ying-Jyuan Ciou \\ Department of Chemical Engineering, National Taiwan University, \\ Taipei 10617, Taiwan
}

\begin{abstract}
This paper deals with the synthesis of mass exchanger networks (MENs) for semicontinuous processes. The starts and endings of available process streams are time-dependent since they usually come from other batch plants. A periodically partitioned stagewise superstructure is presented for modeling the time-dependent mass exchange operations. The proposed stagewise superstructure can handle multiple transferable components and can also be extended to include storage tanks. Not using any heuristics that are based on the concepts of pinch point, the proposed superstructure-based representation for synthesis of semicontinuous MENs is formulated as a mixed-integer nonlinear program (MINLP) for targeting the consumption of external lean mass separating agents. The coke oven gases (COGs) problem from the literature is supplied to demonstrate the applicability of the proposed MEN synthesis method for semicontinuous processes.
\end{abstract}

\section{Introduction}

The indispensable mass exchange operations used in chemical industries include absorption, stripping, extraction, leaching, adsorption, and ion exchange. ${ }^{1}$ A common nature of these mass exchange operations is the transfer of single or multiple components from rich streams, usually process effluent containing valuable materials or undesirable contaminant, into relatively lean mass separating agents (MSAs) to conduct the separations. The mass transfer of these components between different streams is usually executed by contacting the rich streams and lean MSAs in countercurrently direct-contacted mass exchange units.

Recently, some advances on the synthesis of the continuous mass exchanger networks (MENs) have been proposed. ${ }^{2-10,16}$ In the early development, a systematic two-staged procedure for the synthesis of cost-effective MENs was first proposed by El-Halwagi and Manousiouthakis. ${ }^{2}$ Therein, the pinch points, the thermodynamic bottlenecks that limit the extent of mass transfer between the rich streams and the lean MSAs, were located and the minimum consumption of external lean MSAs was also targeted at first. The overall network configuration was then developed to minimize the investment cost in the second stage of synthesis. Thereafter, a linear transshipment model was established for automatic synthesis of MENs with single-component target. ${ }^{3}$ This work was further extended in a later report to include networks for regeneration of recyclable lean streams. ${ }^{4}$ Therein, a mixed-integer nonlinear program (MINLP) was formulated to obtain the minimum cost of massseparating and regenerating agents. Then a mixed-integer linear program was provided to solve the configuration with minimum number of mass exchange units. Recently, Hallale and Fraser ${ }^{5-8}$ presented a method in a series of papers for targeting the capital cost as well as the operating cost of a mass exchanger network, and these costs were further combined to give the total annual cost target. The design of MENs to meet the targets was also discussed in detail. These papers demonstrated that, contrary to previous belief, using the minimum number of units did not necessarily lead to a minimum cost design. ${ }^{5}$ The primary limitation of these sequential approaches, as pointed out by

* To whom all correspondence should be addressed. Tel.: 886-223636194. Fax: 886-2-23623040. E-mail: CCL@ntu.edu.tw.
Papalexandri et al., ${ }^{16}$ was due to the inappropriate consideration of all cost factors and tradeoffs.

In contrast to previous works that simplified the problem by decomposition based on the concept of pinch points, a hyperstructure-based representation of MENs was proposed by Papalexandri et al., ${ }^{16}$ and a superstructure-based representation of MENs was recently proposed by Chen and Hung. 9,10 Therein, the MEN synthesis problem was formulated as a mixed-integer nonlinear program with both network operating and investment costs being optimized simultaneously. The impact of simultaneously minimizing operating and investment costs to waste minimization problems was demonstrated via numerical examples. Meanwhile, some other approaches with quite different representations to the above-mentioned superstructures have also been proposed to solve the MEN and/or HEN (heat exchanger network) synthesis problems, such as that based on the process graph theory, ${ }^{11}$ the state-space approach, ${ }^{12,13}$ the IDEAS, ${ }^{14}$ to name a few. Methods that emphasize the stochastic optimization, such as genetic algorithms, ${ }^{15}$ have also been studied.

Until now, however, there have been only few papers that investigated the synthesis problems for semicontinuous mass exchanger networks. Semicontinuous means that inlets of a continuous process come from other batch processes, and thus, the available inlet streams have different starting and ending times. Wang and Smith ${ }^{17}$ attempted to maximize the driving force in each of the concentration intervals in a time-dependent water network synthesis problem so that water usage is minimized and water consumption can be targeted ahead of any network design by putting time as one of the main process variables. Since the work of Wang and Smith ${ }^{17}$ is a special batch system involving water, a more generalized procedure is needed for the synthesis of semicontinuous process systems involving lean MSAs other than water and for those processes where process streams are continuous within specific periods of times. Recently, Foo et al. ${ }^{18}$ presented the semicontinuous MENs synthesis problem involving MSAs other than water. On the basis of utility target, Foo et al. ${ }^{18}$ used time-dependent composition interval table (TDCIT) to calculate the consumption of external MSAs of the semicontinuous coke oven gases (COGs) problem with three operating modes, including the single operation without storage tanks, the single operation with storage tanks, and the cyclic operation with storage tanks. In their later 
work, Foo et al. ${ }^{19}$ addressed the network structure with storage tanks based on utility target, provided a skill of storing, and discussed the relationship between the units numbers and the amount of utility. Then, Foo et al. ${ }^{20}$ used those skill to design a water network of maximum recovery for a batch process, covering both mass transfer-based and nonmass transfer-based water-using processes. A systematic approach for network synthesis, however, is still desirable for semicontinuous processes.

In this paper, our previous works of superstructure-based MINLP formulation for synthesis of continuously operated MENs will be extended to the synthesis problem for semicontinuous MENs. The stagewise superstructure for continuoustime MEN synthesis proposed by Chen and Hung ${ }^{9,10}$ will be augmented to include storage tanks, and a periodical partitionbased representation will be proposed to handle the timedependent operational characteristics for semicontinuous MENs. The superstructure-based configuration for semicontinuous MEN synthesis problems can also be formulated as a mixed-integer nonlinear program (MINLP). The stagewise superstructure-based representation can handle multiple components straightforwardly and can easily consider single as well as cyclic operation modes. One example from literature, the coke oven gases process with three operational modes, will be illustrated to demonstrate the efficacy of the proposed MEN synthesis method for semicontinuous processes. Though the inclusion of investment costs should be part of the motivation for using a mathematical programming approach, only the targeting of the external lean MSAs under various operational modes will be considered here for discussing the effects of applying storage tanks on different streams. The discussion for designing a continuous operational network incorporated with suitable storage policies for timedependent input streams to minimize the total annual cost will be supplied in a subsequent article.

The structure of this paper is organized as follows. The essential features of the COG sweetening process is first given in the next section. The problem statement for the synthesis of semicontinuous MENs is then elucidated. The periodically partitioned superstructure is, therefore, proposed for simultaneously considering all possible network configurations. A MINLP formulation follows for modeling the synthesis work. A numerical example is thereafter illustrated for demonstrating the proposed design procedure. Finally, a conclusion is made for summary.

\section{The Motivated Case Study: The Coke Oven Gas (COG) Sweetening Process}

The coke oven operation cycle is a batch process that consists of three steps in rough: (i) the coke preparation step, (ii) the coking process step, and (iii) the coke discharging step. After the first coking cycle is completed, the coke oven is charged with another batch of coal blend to start the next cycle. A generic representation of the batch process cycle for coke oven operation is illustrated in Figure $1 .{ }^{18}$ Therein, the coke preparation takes place from time $t_{1}$ to $t_{2}$ and the coking process takes place from time $t_{2}$ to $t_{5}$. The coke is finally discharged from the coke oven between $t_{5}$ and $t_{7}$, and the coke oven is prepared for the next coking cycle.

After the coking process commences shortly, sour COG is released from the coke oven between $t_{3}$ and $t_{5}$ and gets into the COG-sweetening process shortly. The basic objective of the COG sweetening is to remove acidic impurities, primarily hydrogen sulfide, from $\mathrm{COG}$ (a mixture of $\mathrm{H}_{2}, \mathrm{CH}_{4}, \mathrm{CO}, \mathrm{N}_{2}$, $\mathrm{NH}_{3}, \mathrm{CO}_{2}$, and $\mathrm{H}_{2} \mathrm{~S}$ ). Therein, the $\mathrm{H}_{2} \mathrm{~S}$ is an undesirable

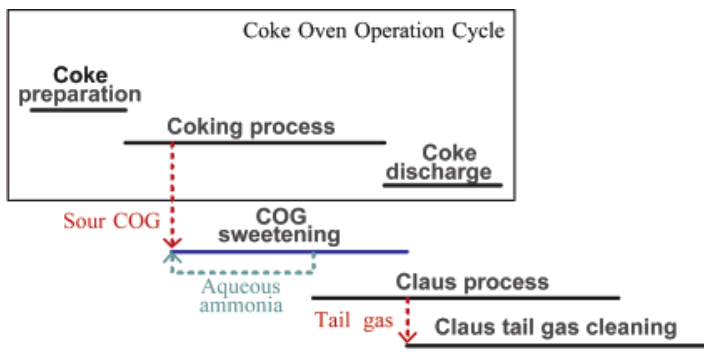

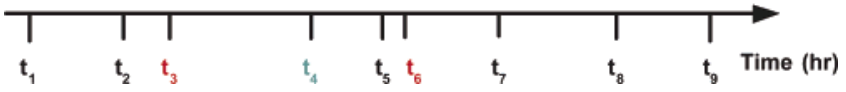

Figure 1. Sour COG sweetening using liquid absorption system. ${ }^{18}$

impurity, because it is corrosive and contributes to $\mathrm{SO}_{2}$ emission when COG is burnt. The existence of ammonia in COG is regenerated into aqueous ammonia, which can absorb $\mathrm{H}_{2} \mathrm{~S}$ and, thus, be suggested as a candidate solvent (the free process lean stream). Note that the regenerated ammonia can supply at $t_{4}$, because it takes times to be produced. Besides ammonia, an external MSA (chilled methanol) is also available for service to supplement the aqueous ammonia solution as needed.

Next, the Claus unit converts the $\mathrm{H}_{2} \mathrm{~S}$ in the enriched acid gas stream coming from the COG sweetening process into elemental sulfur from $t_{4}$ to $t_{8}$. The tail gas, another rich stream, from the Claus unit undergoes further treatment from $t_{6}$ to $t_{9}$. The tail gas from the Claus unit still contains some elemental sulfur because of the thermodynamic limitations in $\mathrm{H}_{2} \mathrm{~S}$ conversion. The flow sheets of the COG sweetening process and the Claus process are shown in Figure $2^{2}$ and Figure $3,{ }^{23}$ respectively. Figure 2 is a probable result that contains two regenerated parts and four mass exchangers. Those exchangers represent all possible matches but not the operational order.

Notably, El-Halwagi and Manousiouthakis ${ }^{2}$ proposed an integrated scheme on the combined treatment of sour $\mathrm{COG}$ stream (R1) and Claus tail gas (R2) with the use of aqueous ammonia (process MSA, S1) and chilled methanol (S2, the external MSA to be used after S1 has been depleted), as depicted in Figure 4.

\section{Problem Statement}

A periodically partitioned method is proposed to overcome the different starting and ending times of each stream in a semicontinuous process, as illustrated in Figure 5, ${ }^{18}$ with two rich and two lean streams having different starting and ending times. From those event times, we can get $N_{\mathrm{P}}=5$ time periods with six time points. The process streams are, therefore, partitioned into five independent parts with the same inlet and outlet compositions and mass flow rates; even the streams may not exist in some time periods. Note that the process MSAs are usually free of charge with a limited amount of supply, and the external MSAs are purchased from outside the plant with given costs. Therefore, it is desirable to use the free process MSAs as much as possible to reduce the purchase cost of external MSAs.

The semicontinuous mass exchanger network synthesis problem addressed in this paper can, thus, be stated as follows: givens are a set of rich process streams $i \in \mathrm{RP}$ in which some transferable components $n \in \mathrm{TC}$ are to be removed away; and a set of lean mass separating agents (MSAs) $j \in \mathrm{LP}$, which are to be used for removing those transferable components in rich streams. Also specified are the flow rates of available rich process streams, $G_{\mathrm{ip}}$, and maximal available rates for lean process streams $L_{j p}^{(\text {up) }}$ input, output, and upper compositions 


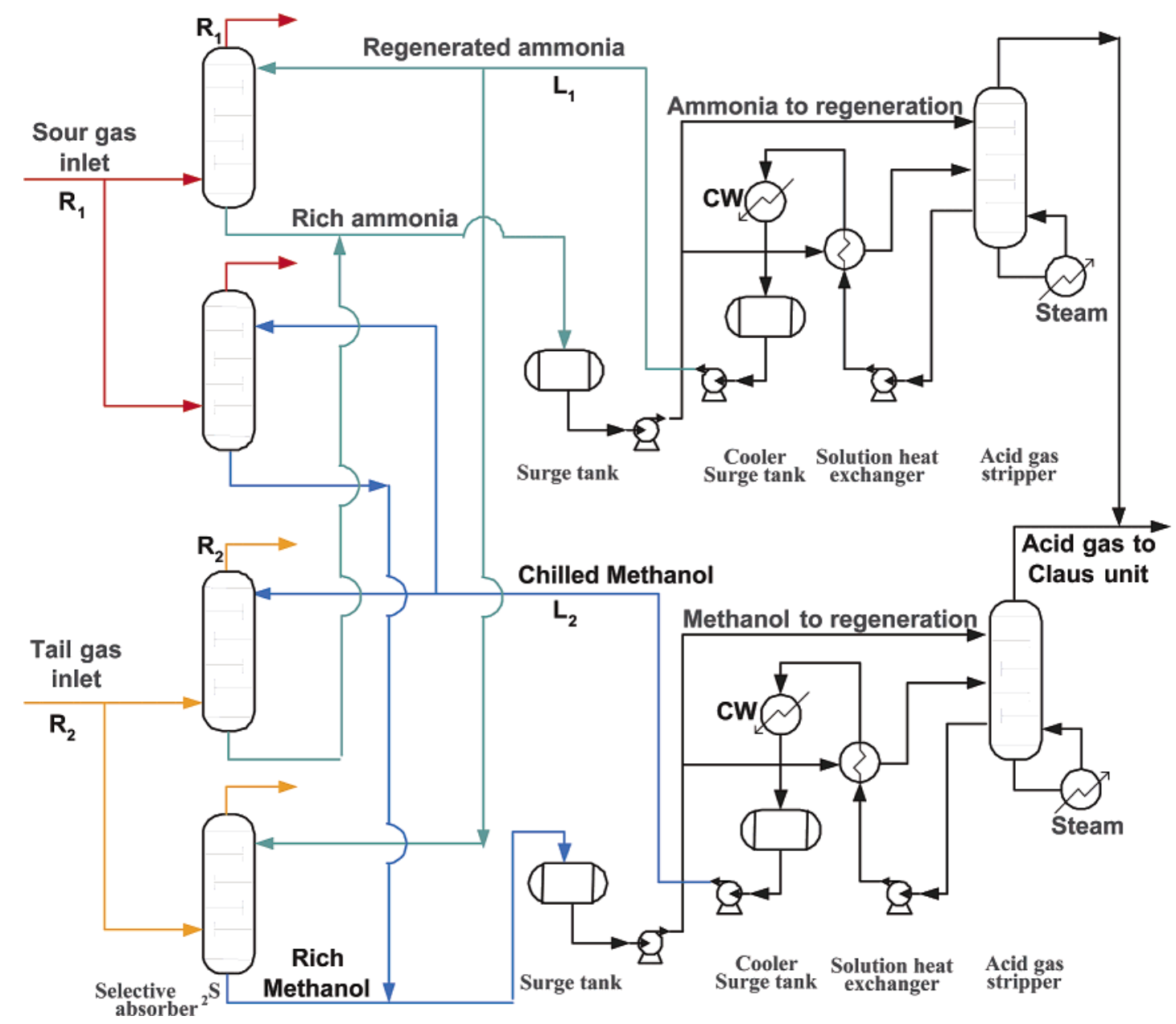

Figure 2. Coke oven gas (COG) sweetening process. ${ }^{2}$

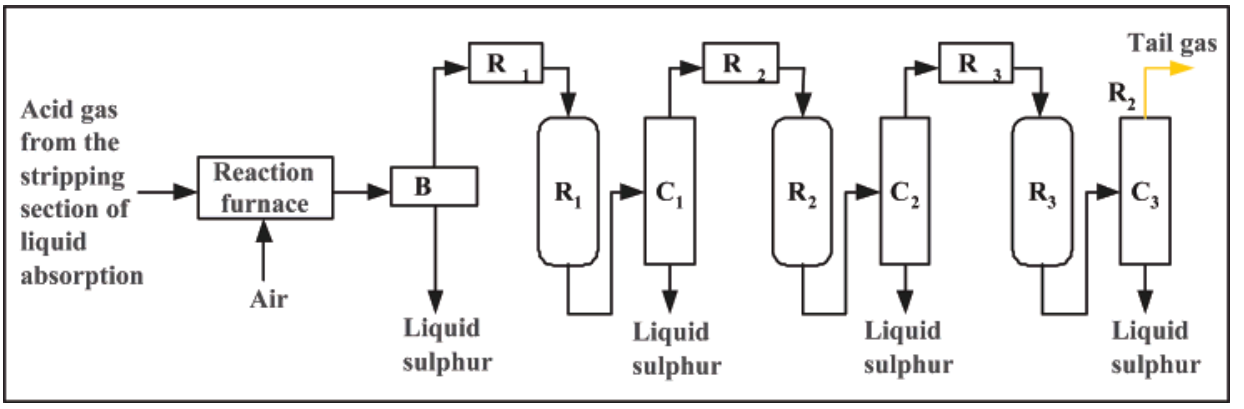

Figure 3. Simple Claus process with a three-reactor bed. ${ }^{23}$

for rich streams, $Y_{i}^{n(\text { in) }}, Y_{i}^{n(\text { out })}$, and $Y_{i}^{n \text { (up) }}$; and input, output, and upper compositions for lean streams, $X_{j}^{n \text { (in) }}, X_{j}^{n \text { (out) }}$, and $X_{j}^{n \text { (up) }}$. Note that the compositions for streams are not dependent on time whenever streams exist or not.

Givens also are linear equilibrium relations for distribution of transferable components between rich and lean streams, $y_{i}^{n} *$ $=m_{i j}^{n} x_{j}^{n}+b_{i j}^{n}$, where $y_{i}^{n} *$ and $x_{j}^{n}$ are equilibrium compositions of component $n$ in $i$ th rich and jth lean streams, respectively, and $m_{i j}^{n}$ and $b_{i j}^{n}$ are associated equilibrium constants, and a minimum composition approach, $\epsilon_{i j}^{n}$. The objective then is to determine the time-dependent mass exchanger network that targets the external mass separating agents. The solution associated with time defines the time-dependent MENs by providing the following: the period-dependent stream matches and the number of units, the targeting mass separating agents and those of mass flow rate, the network configuration and flows for all branches, the mass exchange rates and operating compositions of each mass exchanger unit, and the existence of storage tanks and those of quantity at each time point. The overall network is constructed on the basis of this timedependent information. As pointed out previously, the investment costs will not be addressed in this article, though the inclusion of investment costs in the optimization is part of the motivation for using a mathematical programming approach. For analyzing the implications of applying the storage tanks on the consumption of external MSAs, and for comparing the results with previous works provided by Foo et al., ${ }^{18,19}$ the investment costs are temporarily left out of the problem formulation. This issue will be tackled in the next article.

Several assumptions are made to simplify the semicontinuous MEN synthesis problem, including the following:2,18 the mass flow rate of each stream remains constant throughout the network should it be available; the concentration of each stream remains constant after the action of splitting; the equilibrium 


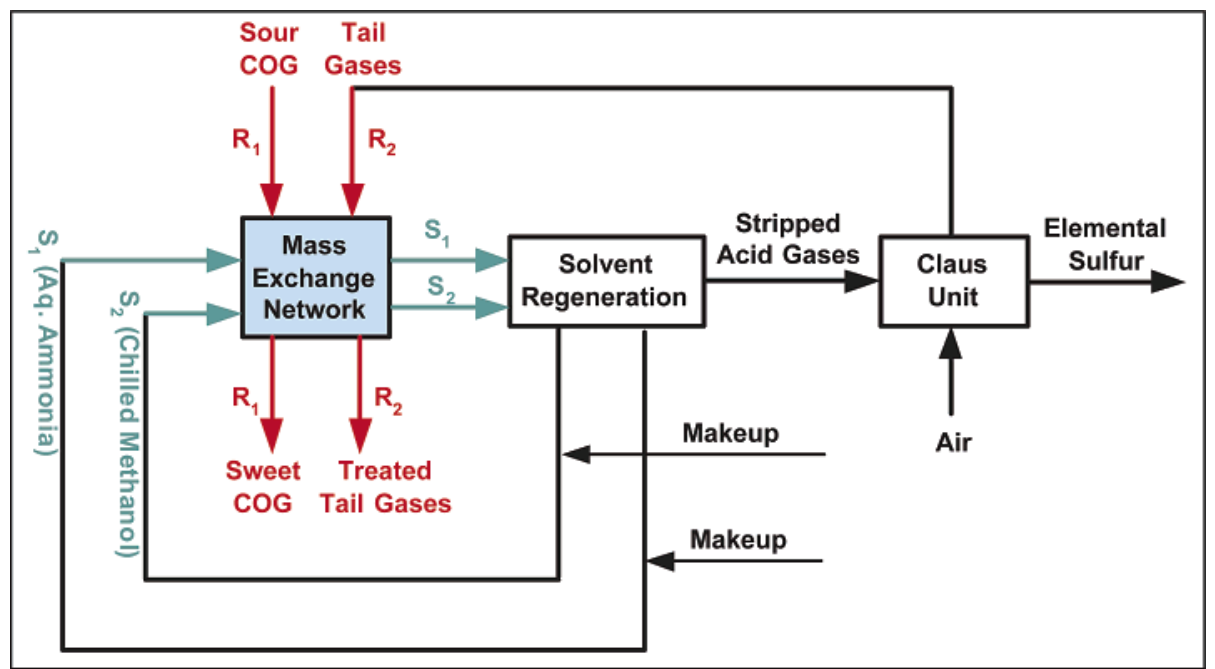

Figure 4. COG sweetening batch process.

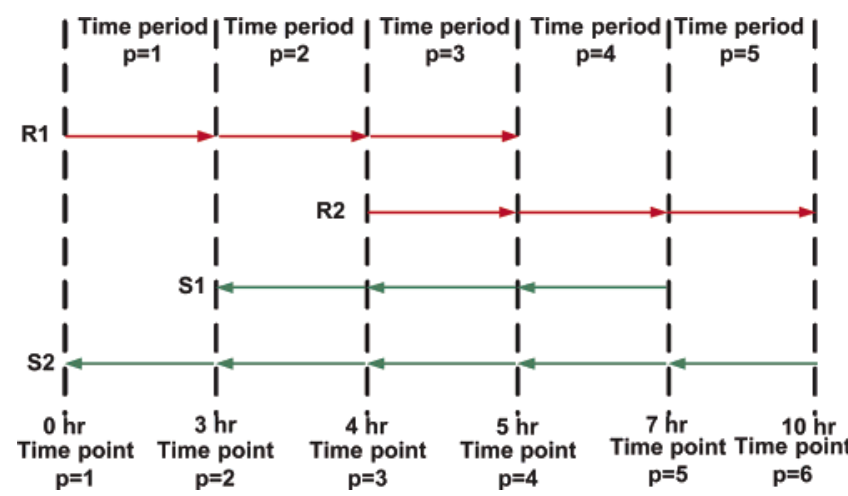

Figure 5. Five periods partition for a semicontinuous process with two rich and two lean streams. ${ }^{18}$

of each transferred component does not depend on the other components; the mass exchange units are countercurrent type; mass exchange between any two rich streams and that between any two lean streams are not allowed; heat integration between streams is not considered; and the network operates at constant pressure. One important assumption that has been adopted in this work is that all process rich and lean streams at an earlier time interval can be stored and used at a later time without technical limitations. Of course, storing of process streams may not always be practical in a typical batch process, as batch operations are normally carried out in sequence, and the process streams will need to be ready for the next operation at the end of an earlier operation. However, we assume that this does not pose a problem in the COG case study, as the COG gas is only to be used as fuel.

\section{Periodically Partitioned Stagewise Superstucture}

The analogue of the pinch analyses for syntheses of heat and mass exchanger networks has been emphasized by several authors. ${ }^{2-8}$ For modeling the time-dependent synthesis problem of semicontinuous mass exchanger networks via simultaneous optimization, we thus directly adapt the stagewise superstructure of Chen and Hung ${ }^{9,10}$ developed for conventional mass exchanger network synthesis in this study. The superstructure focuses one period and selects the maximal rich and lean streams of all periods to design, as in Figure 6 .

In the stagewise superstructure, potential exchanges between any pair of rich and lean streams can occur within each stage, and different sequences for matching streams are allowable by appending several numbers of stages in series. Therein, the outlets of exchange units from splitting of a common stream merge into one and then define the streams as inlets for the next stage. Such as stated by Yee and Grossmann ${ }^{21,22}$ for synthesis of heat exchanger networks (HENs), and by Chen and Hung $^{9,10}$ for synthesis of MENs, and because of the fact that an optimal design usually does not require a large number of exchange units, the number of stages required to model the mass integration is seldom greater than either the maximal number of rich streams $N_{\mathrm{R}}$ or the maximal number of lean streams $N_{\mathrm{L}}$, at all periods. The number of stages is, thus, typically fixed at $N_{\mathrm{S}}=\max \left\{N_{\mathrm{R}}, N_{\mathrm{L}}\right\}$. However, one additional stage is sometimes recommended to search for potential better networks.

For storing or reusing the rich streams, each stream has its own storage tank. At each period, the rich streams may flow into their own storage tanks or be mixed with the flow from specific tanks. This action will change the flow rate for inlet of rich streams of the first stage. Figure 6 shows an example of a stagewise superstructure at the $p$ th period involving two rich streams, two lean streams, and four storage tanks. The two stages are represented by eight mass exchange units, with four possible matches in each stage and variable compositions between each stage. Instead of assuming isocomposition mixing of the split streams, the split streams in the same stage can possess different compositions. This is due to the fact that all compositions and flow rates for lean streams are variables for a typical MEN. The composition material balances around each stage for lean streams will still result in nonlinear constraints, even if we adopt the isocomposition assumption. Thus, one cannot guarantee a convex feasible space defined by a set of linear constraints with the simplified assumption. Notice that the derivation of the stagewise superstructure does not require the identification of pinch point(s) or the partitioning into subnetworks. Furthermore, the model does not rely on any composition interval definition nor any transshipment type constraints.

\section{Model Formulation}

To model the stagewise superstructure for synthesis of the semicontinuous mass exchange networks to minimize the external mass separating agents, the indices and sets, parameters, and variables are given in Notations. With these definitions, we can formulate the stagewise superstructure model for synthesizing the periodically dependent mass exchanger networks for a semicontinuous process. 


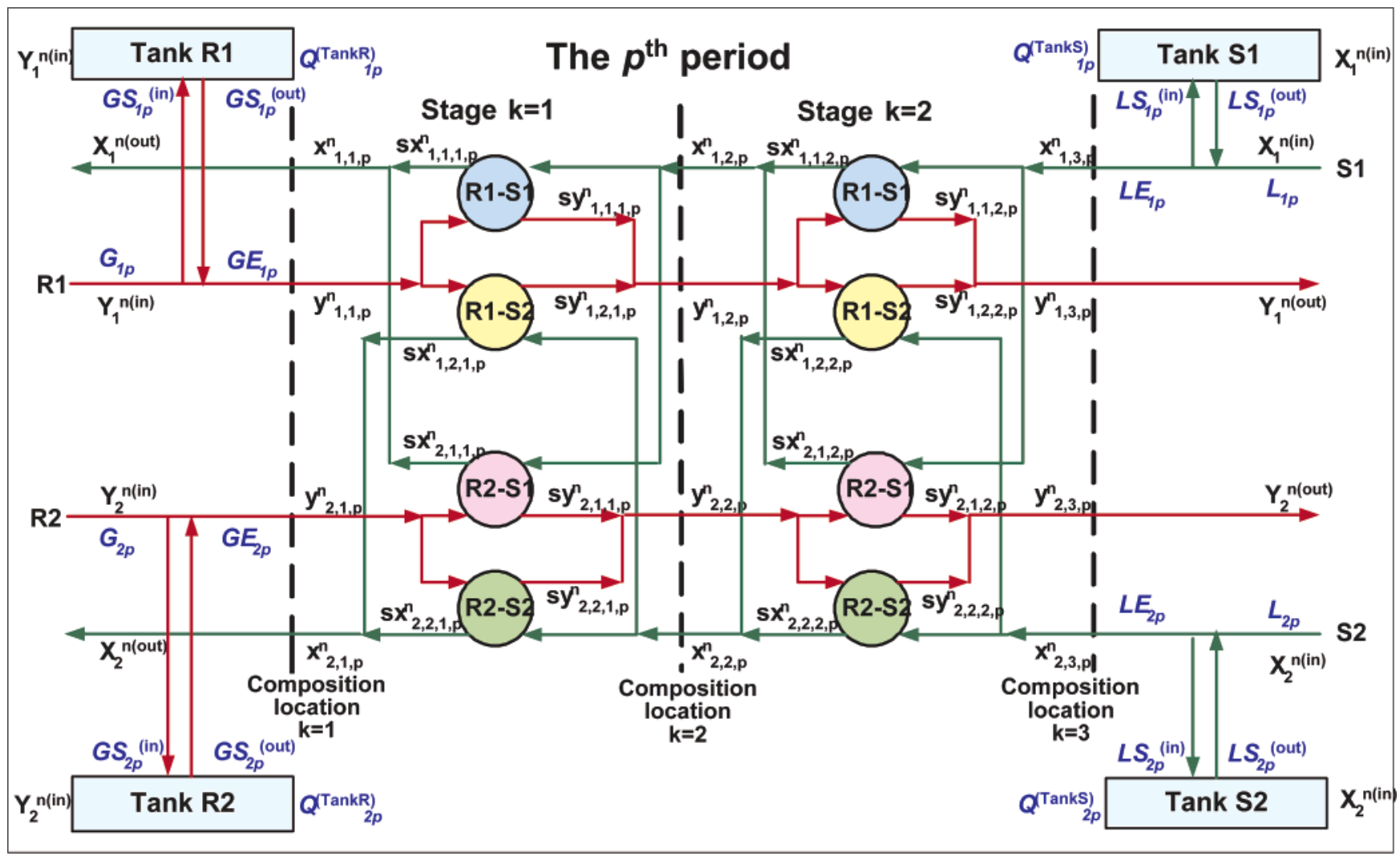

Figure 6. Two-stage superstructure for mass exchange network synthesis with two-rich/two-lean streams and associated storage tanks.

5.1. Overall Mass Balances for Transferable Components over the Whole Network. Suppose each of the rich and lean streams is equipped with its own storage tank for adaptive operation during various periods. Since the stream rates are period dependent, part of the input rich or lean stream rate can be stored temporally and then released from the storage tank later for supplying economic and smooth operation. The exact rate for the $i$ th and $j$ th stream flowing into the stage during period $p, \mathrm{GE}_{i p}$ and $\mathrm{LE}_{j p}$, respectively, can be calculated,

$$
\begin{aligned}
\mathrm{GE}_{i p} & =G_{i p}-\mathrm{GS}_{i p}^{(\mathrm{in})}+\mathrm{GS}_{i p}^{(\text {out })} \quad \forall i \in \mathrm{RP}, p \in \mathrm{TP} \\
\mathrm{LE}_{j p} & =L_{j p}-\mathrm{LS}_{j p}^{\text {(in) }}+\mathrm{LS}_{j p}^{\text {(out) }} \quad \forall j \in \mathrm{LP}, p \in \mathrm{TP}
\end{aligned}
$$

where $\mathrm{GS}_{i p}^{(\mathrm{in})}, \mathrm{GS}_{i p}^{(\mathrm{out})}, \mathrm{LS}_{j p}^{(\mathrm{in})}$, and $\mathrm{LS}_{j p}^{(\mathrm{out})}$, respectively, denote the rates for inlet rich stream $i$ or lean stream $j$ flowing into or out of their storage tanks during the $p$ th period. Suppose each stream keeps the same inlet and outlet compositions at all periods should it be available. An overall mass balance during period $p$ can then be formulated to ensure sufficient exchange of all transferred components for all rich and lean streams.

$$
\begin{aligned}
&\left(Y_{i}^{n(\mathrm{in})}-Y_{i}^{n(\mathrm{out})}\right) \mathrm{GE}_{i p}= \sum_{\forall k \in \mathrm{ST} \forall j \in \mathrm{LP}} \sum_{i j k p} M^{n} \forall i \in \mathrm{RP}, p \in \mathrm{TP}, n \in \mathrm{TC} \\
&\left(X_{j}^{n(\text { out })}-X_{j}^{n(\mathrm{in})}\right) \mathrm{LE}_{j p}=\sum_{\forall k \in \mathrm{ST}} \sum_{\forall i \in \mathrm{RP}} M_{i j k p}^{n} \\
& \forall j \in \mathrm{LP}, p \in \mathrm{TP}, n \in \mathrm{TC} \text { (2) }
\end{aligned}
$$

The first constraint specifies that the overall transferable requirement for component $n$ of each rich stream must be equal to the sum of exchange loads for the component that is exchanged with other lean process streams or external MSAs at all potential mass exchange units. The second constraint reveals the similar relation for component $n$ in lean stream $j$ should it be available during period $p$.

5.2. Mass Balances for Transferable Components in each Stage. The mass balance of each stream in each stage is used to determine the composition of each transferable component. For a superstructure with $N_{\mathrm{S}}$ stages, $N_{\mathrm{S}}+1$ levels of composition are involved. Note that the index $k$ is used to represent the stage and the composition location in the superstructure. For each stage $k$, the composition at location $k$ of each stream is higher than the composition at location $k+1$. The component and the mass balance for each stream in each stage during period $p$ can be stated as follows.

$$
\begin{aligned}
&\left(y_{i k p}^{n}-y_{i, k+1, p}^{n}\right) \mathrm{GE}_{i p}= \sum_{\forall j \in \mathrm{LP}} M_{i j k p}^{n} \\
& \forall i \in \mathrm{RP}, k \in \mathrm{ST}, p \in \mathrm{TP}, n \in \mathrm{TC} \\
&\left(x_{j k p}^{n}-x_{j, k+1, p}^{n}\right) \mathrm{LE}_{j p}= \sum_{\forall i \in \mathrm{RP}} M_{i j k p}^{n} \\
& \forall j \in \mathrm{LP}, k \in \mathrm{ST}, p \in \mathrm{TP}, n \in \mathrm{TC}
\end{aligned}
$$

For each stage, each rich stream splits into $N_{\mathrm{L}}$ streams to match with $N_{\mathrm{L}}$ lean streams, respectively. New variables, $g_{i j k p}$ and $/_{i j k p}$, are used to represent the split mass rates for rich $i$ and lean $j$ streams at stage $k$ during period $p$.

$$
\begin{gathered}
\mathrm{GE}_{i p}=\sum_{\forall j \in \mathrm{LP}} g_{i j k p} \quad \forall i \in \mathrm{RP}, k \in \mathrm{ST}, p \in \mathrm{TP} \\
\mathrm{LE}_{j p}=\sum_{\forall i \in \mathrm{RP}} l_{i j k p} \quad \forall j \in \mathrm{LP}, k \in \mathrm{ST}, p \in \mathrm{TP}
\end{gathered}
$$

5.3. Mass Balances for Transferable Components in Each Exchange Unit. A component mass balance is needed for each local exchange unit. The inlet composition of each unit is the same as the inlet composition at each stage, because we assume 
that the action of splitting does not affect the composition of each stream. New composition variables, $s y_{i j k}^{n}$ and $s x_{i j k}^{n}$, are defined to express outlet compositions of units, as illustrated in Figure 6. The unit mass balance is stated in the following.

$$
\begin{aligned}
&\left(y_{i k p}^{n}-s y_{i j k p}^{n}\right) g_{i j k p}= M_{i j k p}^{n} \\
& \forall i \in \mathrm{RP}, j \in \mathrm{LP}, k \in \mathrm{ST}, p \in \mathrm{TP}, n \in \mathrm{TC} \\
&\left.\left(s x_{i j k p}^{n}-x_{j, k+1, p}^{n}\right)\right)_{i j k p}=M_{i j k p}^{n} \\
& \forall i \in \mathrm{RP}, j \in \mathrm{LP}, k \in \mathrm{ST}, p \in \mathrm{TP}, n \in \mathrm{TC}
\end{aligned}
$$

Notice that the balance equations around all mixers from split streams are not necessary since these equations are redundant to eqs $3-5$.

5.4. Remaining Mass for Transferable Components for Each Storage Tank. The remaining mass of each storage tank during each period $p$ is relevant for designing suitable tank size. The remaining mass of each storage tank $i$ at period $p, Q_{i, p+1}^{(\text {TankR) }}$, is equal to the tank's initial mass, $Q_{i, p}^{\text {(TankR) }}$, plus the input mass from its corresponding stream minus the output mass from the storage. Note also that the remaining mass of each storage tank $i$ at period $p$ is also the initial mass of the storage at subsequent period $p+1$. These constraints also apply for storage tanks for lean streams.

$$
\begin{array}{ll}
Q_{i, p+1}^{(\text {TankR })}=Q_{i p}^{(\text {TankR })}+\left(\mathrm{GS}_{i p}^{(\text {in })}-\mathrm{GS}_{i p}^{(\text {out })}\right) t_{p} & \forall i \in \mathrm{RP}, p \in \mathrm{TP} \\
Q_{j, p+1}^{\text {(TankS) }}=Q_{j p}^{\text {(TankS) }}+\left(\mathrm{LS}_{j p}^{(\mathrm{in})}-\mathrm{LS}_{j p}^{(\text {out })}\right) t_{p} & \forall j \in \mathrm{LP}, p \in \mathrm{TP}
\end{array}
$$

Here, $t_{p}$ is the elapsed time of period $p$. Also note that both the initial mass at the first time point $p=1$ and the remaining mass at the final time point $N_{\mathrm{P}}+1$ should be zero for single-batch operation, and these two quantities should be equal for cyclic operations. A binary parameter $Z^{(\mathrm{cyc})}$ is used where a zero value represents single-batch operation and a value $=1$ denotes the design for cyclic operations. The initial mass at the first time point $p=1$ can, thus, be stated as follows.

$$
\begin{array}{ll}
Z^{(\mathrm{cyc})} Q_{i 1}^{\text {(TankR) }}=Q_{i, \mathrm{NP}}^{\text {(TankR) }}+\left(\mathrm{GS}_{i, \mathrm{NP}}^{(\text {in })}-\mathrm{GS}_{i, \mathrm{NP}}^{(\text {out })} t_{\mathrm{NP}}\right. & \forall i \in \mathrm{RP} \\
Z^{(\mathrm{cyc})} Q_{j 1}^{\text {(TankS })}=Q_{j, \mathrm{NP}}^{\text {(TankS) }}+\left(\mathrm{LS}_{j, \mathrm{NP}}^{(\mathrm{in})}-\mathrm{LS}_{j, \mathrm{NP}}^{\text {(out) }}\right) t_{\mathrm{NP}} \quad \forall j \in \mathrm{LP}
\end{array}
$$

In this equation, $Z^{(\mathrm{cyc})}$ with zero value would make $Q_{i 1}^{\text {(TankR) }}$ and $Q_{j 1}^{\text {(TankS) }}$ become zero, and this result also makes $Q_{i, \mathrm{~N} p+1}^{(\text {TankR) }}$ and $Q_{j, \mathrm{~N} p+1}^{(\text {TankS) }}$ be zero. Equations 6 and 7 would also ensure $Q_{i, \mathrm{~N} p+1}^{\text {(TankR) }}$ $=Q_{i 1}^{(\text {TankR) }}$ and $Q_{j, \mathrm{~N} p+1}^{(\text {TankS) }}=Q_{j 1}^{(\text {TankS) }}$ should $Z^{(\mathrm{cyc})}=1$. It is very sensible for single-batch operation, because the mass of the storage tank must be zero at the beginning, and the mass in the storage tank should be run out at the end. The constraint is shown below, where $\Gamma$ is a large positive upper bound.

$$
Q_{i 1}^{(\text {TankR })}, Q_{j 1}^{(\text {TankS })} \leq \Gamma Z^{(\text {cyc })} \quad \forall i \in \mathrm{RP}, j \in \mathrm{LP}
$$

5.5. Existence of Each Storage Tank. Considering the practical limitations, some specific rich or process lean streams may be forbidden or not worthwhile for temporal storage. However, for studying the effects of various storage policies on rich and/or process lean streams, as elucidated in the subsequently supplied case study, we assume all streams can be independently accumulated and distributed at a later time without any technical difficulty, and it does not need to take the additional storage cost into account. Binary parameters, $Z_{i}^{\text {(TankR) }}$ and $Z_{j}^{\text {(TankS) }}$, are used to denote the existence of storage tanks. These parameters will take a value of zero for the case of forbidden storage to guarantee zero remain the value at all times. The result of zero $Q_{i p}^{\text {(TankR) }}$ (or zero $Q_{j p}^{\text {(TankS) }}$ ) value would turn $\mathrm{GS}_{i p}^{\text {(in) }}$ and $\mathrm{GS}_{i p}^{\text {(out) }}$ (or $\mathrm{LS}_{j p}^{\text {(in) }}$ and $\mathrm{LS}_{j p}^{\text {(out) }}$ ) into zero. Thus, $\mathrm{GE}_{i p}$ will then be reduced into $G_{i p}$ (and $\mathrm{LE}_{j p}$ into $L_{j p}$ ) under such a case.

$$
\begin{array}{ll}
Q_{i p}^{(\text {TankR })} \leq \Gamma Z_{i}^{\text {(TankR) }} & \forall i \in \mathrm{RP}, p \in \mathrm{TP} \\
Q_{j p}^{\text {(TankS) }} \leq \Gamma Z_{j}^{\text {(TankS })} \quad \forall j \in \mathrm{LP}, p \in \mathrm{TP}
\end{array}
$$

5.6. Assignment of Superstructure Inlet/Outlet Compositions. The given inlet/outlet compositions of rich and lean process streams are assigned as the inlet/outlet compositions to the superstructure. For rich streams, the inlet of superstructure corresponds to composition location $k=1$, and the outlet of superstructure corresponds to composition location $k=N_{\mathrm{S}}+$ 1. While for lean streams, the inlet corresponds to location $k=$ $N_{\mathrm{S}}+1$, and the outlet of superstructure corresponds to composition location $k=1$.

$$
\begin{array}{ll}
Y_{i}^{n(\mathrm{in})}=y_{i 1 p}^{n}, Y_{i}^{n(\text { out })}=y_{i, \mathrm{NS}+1, p}^{n} & \forall i \in \mathrm{RP}, p \in \mathrm{TP}, n \in \mathrm{TC} \\
X_{j}^{n(\mathrm{in})}=x_{j, \mathrm{NS}+1, p}^{n}, X_{j}^{n \text { (out) }}=x_{j 1 p}^{n} \quad \forall j \in \mathrm{LP}, p \in \mathrm{TP}, n \in \mathrm{TC}
\end{array}
$$

5.7. Feasibility of the Transferable Components. Constraints are also needed to guarantee a monotonic decrease of all compositions at successive stages, such as,

$$
\begin{array}{ll}
y_{i k p}^{n} \geq y_{i, k+1, p}^{n} & \forall i \in \mathrm{RP}, k \in \mathrm{ST}, p \in \mathrm{TP}, n \in \mathrm{TC} \\
x_{j k p}^{n} \geq x_{j, k+1, p}^{n} & \forall j \in \mathrm{LP}, k \in \mathrm{ST}, p \in \mathrm{TP}, n \in \mathrm{TC}
\end{array}
$$

5.8. Logical Constraints. Logical constraints and binary variables, $z p_{i j k p}$, are used to determine the existence or absence of process matches $(i, j)$ in stage $k$ at period $p$. An integer value of 1 for binary variable $z p_{i j k p}$ designates that a match between rich stream $i$ and lean stream $j$ in stage $k$ at period $p$ is present in the optimal network, whereas the binary variable $z_{i j k}$ represents the existence of an $(i, j)$ match in stage $k$ in the overall network configuration. The constraints are as follows, where $\underline{M}$ and $\bar{M}$ are positive lower and upper bounds for the exchangers' load, respectively.

$$
\begin{aligned}
& \underline{M}_{z p_{i j k p}} \leq \sum_{\forall n \in \mathrm{TC}} \underline{M}_{i j k p}^{n} \leq \bar{M} z p_{i j k p} \\
& \forall i \in \mathrm{RP}, j \in \mathrm{LP}, k \in \mathrm{ST}, p \in \mathrm{TP}, n \in \mathrm{TC} \\
& z p_{i j k p} \leq z_{i j k} \leq \sum_{\forall p \in \mathrm{TP}} z p_{i j k p} \quad \forall i \in \mathrm{RP}, j \in \mathrm{LP}, k \in \mathrm{ST}, p \in \mathrm{TP}
\end{aligned}
$$

Similarly, binary variables, $z r_{i p}^{\text {(in) }}$ and $z r_{i p}^{\text {(out) }}$ or $z s_{j p}^{\text {(in) }}$ and $z s_{j p}^{\text {(out) }}$, are used to denote the status of rich stream $i$ or lean stream $j$ flowing into or discharging from its own storage tank. The stored rate has the normal input rate as its upper bound; and the discharging rate is also limited by the remains in the storage tank, where $t_{p}$ is the elapsed time of period $p$. Meanwhile, the 
actions of storage and discharge are disjunctive at the same time. The following equations summarize these restraints.

$$
\left.\begin{array}{rl}
\mathrm{GS}_{i p}^{(\mathrm{in})}-G_{i p} z r_{i p}^{\text {(in) }} & \leq 0 \\
G \mathrm{~S}_{i p}^{(\text {out })} t_{p}-Q_{i p}^{\text {(TankR) }} z r_{i p}^{(\text {out })} & \leq 0 \\
z r_{i p}^{\text {(in) }}+z r_{i p}^{\text {(out) }} & \leq 1
\end{array}\right\} \quad \forall i \in \mathrm{RP}, p \in \mathrm{TP}
$$

5.9. Feasibility Constraints of the Equilibrium Relationships. Linear equilibrium relations are adopted here for distribution of transferable component $n$ between rich $i$ and lean $j$ streams, $y_{i}^{n} *=m_{i j}^{n} x_{j}^{n}+b_{i j}^{n}$. The feasibility constraints of the equilibrium relationships ensure positive driving forces, $d y x i_{i j k p}^{n}$ and $d y x o_{i j k p}^{n}$, for the potential $(i, j)$ match in stage $k$ during period $p$ at the rich and lean sides, respectively. Binary variables are used for these constraints to ensure that only the nonnegative driving forces exist for existing matches where the associated binary variables all equal 1 . If a match does not occur, the associated binary variable equals zero and the large positive upper bound $\Gamma$ can deem the equation redundant. In these equations, a streams-and-component dependent minimum composition approach $\epsilon_{i j}^{n}$ is also chosen so that feasible mass transfer in a finite number of equilibrium stages or a finite area can be achieved in each transfer unit. ${ }^{10}$

$$
\begin{gathered}
d y x i_{i j k p}^{n}, d y x o_{i j k p}^{n} \geq m_{i j}^{n} \epsilon_{i j}^{n} \\
d y x i_{i j k p}^{n} \leq y_{i k p}^{n}-\left(m_{i j}^{n} s x_{i j k p}^{n}+b_{i j}^{n}\right)+\Gamma\left(1-z p_{i j k p}\right) \\
d y x o_{i j k p}^{n} \leq s y_{i j, k+1, p}^{n}-\left(m_{i j}^{n} x_{j, k+1, p}^{n}+b_{i j}^{n}\right)+\Gamma\left(1-z p_{i j k p}\right) \\
\forall i \in \mathrm{RP}, j \in \mathrm{LP}, k \in \mathrm{ST}, p \in \mathrm{TP}, n \in \mathrm{TC}
\end{gathered}
$$

5.10. Bounds on Variables. Possibly lean streams may come from the process; then bounds for available mass of lean process streams should be set. Bounds for final compositions of rich and lean streams comply with rules of environmental protection.

$$
\begin{gathered}
L_{j p} \leq L_{j p}^{\text {(up) }} X_{j}^{n(\text { out })} \leq X_{j}^{n(\text { up })} \quad \forall j \in \mathrm{LP}, p \in \mathrm{TP}, n \in \mathrm{TC} \\
L_{j p}^{\text {(up) }} \leq L_{j p}^{\text {(up) }} \quad \forall i \in \mathrm{RP}, n \in \mathrm{TC}
\end{gathered}
$$

5.11. Optional Constraints. Some additional constraints such as no stream splits, forbidden matches, and required and restricted matches can be easily included in this model. For example, the stream splitting can be prevented by constraining the number of matches for split streams in each stage, such as,

$$
\begin{array}{cl}
\sum_{\forall i \in \mathrm{RP}} z p_{i j k p} \leq 1 & \forall j \in \mathrm{LP}, k \in \mathrm{ST}, p \in \mathrm{TP} \\
\sum_{\forall j \in \mathrm{LP}} z p_{i j k p} \leq 1 \quad \forall i \in \mathrm{RP}, k \in \mathrm{ST}, p \in \mathrm{TP}
\end{array}
$$

\begin{tabular}{|c|c|c|c|c|c|c|c|}
\hline $\begin{array}{c}\text { rich } \\
\text { stream }\end{array}$ & descrip & $\begin{array}{l}G_{i}^{\text {(tot }} \\
(\mathrm{kg})\end{array}$ & $\begin{array}{c}y_{i}^{(\mathrm{in})} \\
\text { (mass frac } \\
\end{array}$ & $\begin{array}{r}y_{i}^{\text {ou }} \\
\text { (mass }\end{array}$ & & $\begin{array}{l}\text { start } \\
t^{s}(\mathrm{~h}) \\
\end{array}$ & $\begin{array}{l}\text { stop } \\
t^{f}(\mathrm{~h})\end{array}$ \\
\hline$R_{1}$ & $\mathrm{CO}$ & 3240 & 0.0700 & 0.0 & & 0 & 5 \\
\hline$R_{2}$ & tail gases & 360 & 0.0510 & 0.00 & & 4 & 10 \\
\hline $\begin{array}{l}\text { lean } \\
\text { stream }\end{array}$ & descrip & $\begin{array}{l}L_{j}^{(\mathrm{tot})} \\
(\mathrm{kg})\end{array}$ & $\begin{array}{c}x_{j}^{\text {(in) }} \\
\text { (mass frac) }\end{array}$ & $\begin{array}{c}x_{j}^{\text {(out) }} \\
\text { (mass frac) }\end{array}$ & $\begin{array}{l}\text { start } \\
t^{\mathrm{s}}(\mathrm{h})\end{array}$ & $\begin{array}{l}\text { stop } \\
t^{\mathrm{f}}(\mathrm{h})\end{array}$ & $\begin{array}{l}\mathrm{UC}_{j} \\
(\$ / \mathrm{kg})\end{array}$ \\
\hline $\begin{array}{l}S_{1} \\
S_{2}\end{array}$ & $\mathrm{~m}$ & $\begin{array}{l}82 \\
\infty\end{array}$ & 0.0002 & $\begin{array}{l}0.0310 \\
0.0035\end{array}$ & 3 & 7 & 0 \\
\hline
\end{tabular}

The maximum total number of mass exchanger units can be limited by adding an upper bound for selected exchangers, MEU, in the following constraint.

$$
\sum_{\forall i \in \mathrm{RP} \forall j \in \mathrm{LP} \forall k \in \mathrm{ST}} \sum_{i j k} \leq \mathrm{MEU}
$$

Table 1. Stream Data for the Semicontinuous COG Process ${ }^{18}$

Table 2. Availability of Time-Dependent Rich and Lean Streams

\begin{tabular}{cccccc}
\hline period & 1 & 2 & 3 & 4 & 5 \\
duration time (h) & $0-3$ & $3-4$ & $4-5$ & $5-7$ & $7-10$ \\
elapsed time $t_{p}$ & 3 & 1 & 1 & 2 & 3 \\
\hline$Z_{1 p}^{\text {rich) }}$ & 1 & 1 & 1 & 0 & 0 \\
$Z_{2 p}^{\text {rich) }}$ & 0 & 0 & 1 & 1 & 1 \\
$Z_{1 p}^{\text {lean }}$ & 0 & 1 & 1 & 1 & 0 \\
$Z_{2 p}^{\text {(lean) }}$ & 1 & 1 & 1 & 1 & 1
\end{tabular}

Other restrictions can also be considered by assigning suitable values for specific integer variables. For example, should the match between rich stream $i=1$ and lean stream $j=2$ be not allowable, then one can assign $z_{12 k}=0, \forall k \in \mathrm{ST}$.

5.12. Objective Function and MINLP Formulation. A natural objective for network design is to minimize the total expense of external mass separating agents for single operation or for cyclic operations, as follows, where $\boldsymbol{x}$ and $\Omega$ denote the set of all design variables and the feasible space defined by all constraints, eqs $1-17$, respectively, and $\mathrm{UC}_{j}$ is the unit cost for MSA $j$. Note that the cost of process MSAs could be set as zero. Furthermore, all of the external MSAs can have $\mathrm{UC}_{j}=1$, and thus, the design objective becomes minimizing the overall external MSAs.

$$
\begin{gathered}
\min _{x \in \Omega} J=\sum_{\forall p \in \mathrm{TP} \forall j \in \mathrm{LP}} \sum_{\mathrm{UC}_{j} L_{j p} t_{p}} \\
\Omega=\{\boldsymbol{x} \mid \text { set of constrains, eqs } 1-17\}
\end{gathered}
$$

\section{Numerical Example: Sweetening of COG}

This example, originated from by El-Halwagi and Manousiouthakis in 1989,2 involves the simultaneous removal of $\mathrm{H}_{2} \mathrm{~S}$ $(n=1)$ and $\mathrm{CO}_{2}(n=2)$ from the coke oven gas $\left(R_{1}\right.$, a mixture $\mathrm{H}_{2}, \mathrm{CH}_{4}, \mathrm{CO}, \mathrm{N}_{2}, \mathrm{NH}_{3}, \mathrm{CO}_{2}$, and $\mathrm{H}_{2} \mathrm{~S}$ ) and the Claus unit tail gas $\left(R_{2}\right)$. The $\mathrm{H}_{2} \mathrm{~S}$ should be removed when the COG is used as a fuel to reduce the emission of corrosive $\mathrm{SO}_{2}$. The presence of ammonia in COG led to the utilization of aqueous ammonia as a free process lean stream, $S_{1}$. The chilled methanol is used as an external MSA, $S_{2}$. The purification of COG involves washing the sour COG with sufficient aqueous ammonia and chilled methanol to absorb required amounts of $\mathrm{H}_{2} \mathrm{~S}$. The acid gases are then stripped from solvents, and the regenerated MSAs are recirculated. The stripped acid gases are fed to a Claus unit, where the sulfur is recovered from $\mathrm{H}_{2} \mathrm{~S}$. The tail gas leaving the Claus unit ought to be treated for partial removal of uncovered $\mathrm{H}_{2} \mathrm{~S}$. Furthermore, the $\mathrm{CO}_{2}$ often occurs in $\mathrm{COG}$ in relatively large compositions, but it is not considered here.

The basic features of the process and problem data are provided in Table $1,{ }^{18}$ which is modified from the data for continuous operational scenario, ${ }^{2}$ where $G_{i}^{\text {(tot) }}$ is the total available amount for rich stream $i$ and $L_{j}^{\text {(tot) }}$ is the upper limit for lean stream $j$ during one operational cycle (that is, $10 \mathrm{~h}$ ). The availabilities of these streams in various time periods are denoted by binary parameters, $Z_{i p}^{\text {(rich) }}$ and $Z_{j p}^{\text {(lean) }}$, where a unity 


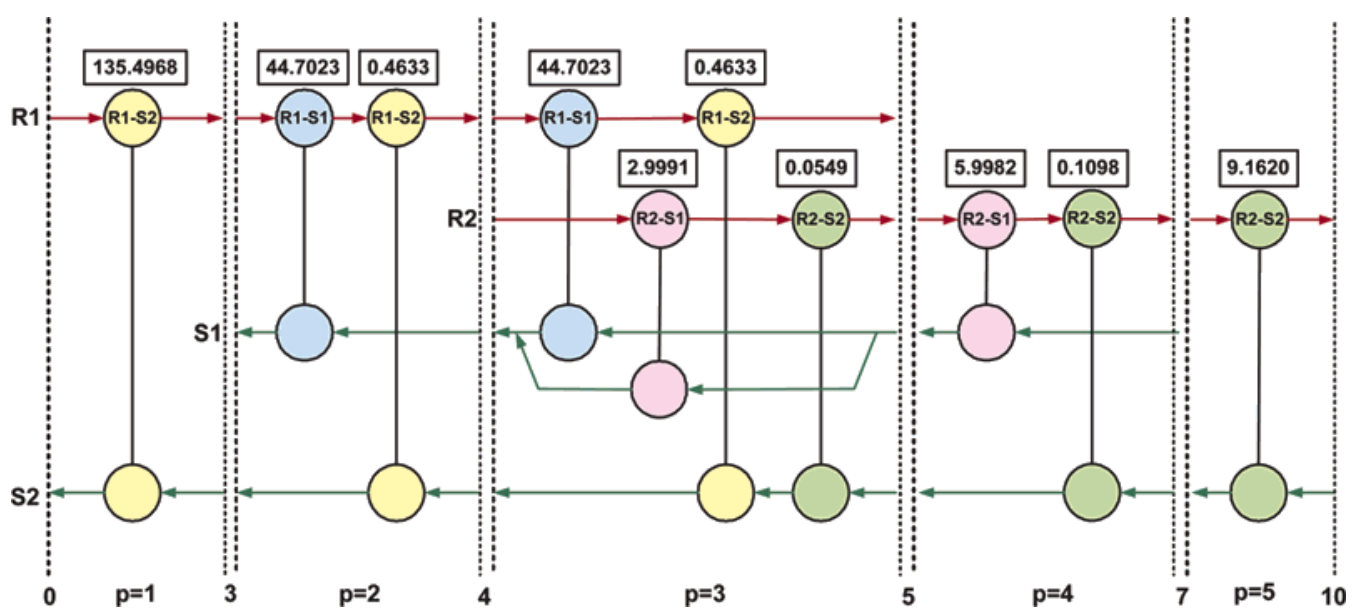

Figure 7. MEN structure of single batch without storage tanks by proposed superstructure.

value denotes the existence of rich stream $i$ or lean stream $j$ in period $p$, as shown in Table 2. It is assumed that the total amount of each stream in the whole operational cycle is uniformly distributed within the available elapsed times. Thus, the available flow rates of these rich and lean streams, $G_{i p}$ and $L_{j p}^{\text {(up) }}$, can be calculated by the following equations.

$$
\begin{aligned}
G_{i p}(\mathrm{~kg} / \mathrm{h}) & =\frac{G_{i}^{(\mathrm{tot})}(\mathrm{kg})}{\sum_{\forall p \in \mathrm{TP}} t_{p} Z_{i p}^{(\mathrm{rich})}} Z_{i p}^{\text {(rich) }} \quad \forall i \in \mathrm{RP} \\
L_{j p}^{(\mathrm{up})}(\mathrm{kg} / \mathrm{h}) & =\frac{L_{j}^{(\mathrm{tot})}(\mathrm{kg})}{\sum_{\forall p \in \mathrm{TP}} t_{p} Z_{j p}^{(\text {lean })}} Z_{j p}^{\text {(lean })} \quad \forall j \in \mathrm{LP}
\end{aligned}
$$

The mean flow rates of rich streams and the maximum rates for lean streams can, thus, be computed as follows should they be available:

$$
G_{1 p}=648 ; \quad G_{2 p}=60 ; \quad L_{1 p}^{(\text {up })}=2070 ; \quad L_{2 p}^{(\text {up })}=\infty(\mathrm{kg} / \mathrm{h})
$$

Notably, the total limiting amount of the process lean stream should be multiplied with its duration time, $L_{1 p}^{\text {(up) }} t_{p}$. The equilibrium solubility data for $\mathrm{H}_{2} \mathrm{~S}$ in aqueous ammonia and methanol can be correlated by the following relations.

$y_{i}=\left\{\begin{array}{l}1.45 x_{1} \text { in aqueous ammonia } \\ 0.26 x_{2} \text { in methanol }\end{array} i=1\right.$ (COG), 2 (tailgas)

Perforated-plate columns are considered for both solvents, and a minimum composition difference of $\epsilon=0.0001$ is selected to determine feasible mass exchange at the inlet and outlet of each potential mass exchanger unit.

We consider first the design for single operation without/ with storage tanks and then the optimal design for cyclic operations. For solving the MINLP formulation for the semicontinuous MEN synthesis model, the general algebraic modeling system $(\mathrm{GAMS})^{24}$ is used as the main solution tool. The MINLP and NLP solvers are SBB and SNOPT, respectively.

6.1. Single Operation without Storage Tanks. For starters, under the condition of single operation without storage tanks (i.e., $Z_{i}^{(\text {TankR) }}=Z_{j}^{(\text {TankS) }}=Z^{\text {(cyc) }}=0$ for all $i \in \mathrm{RP}, j \in \mathrm{LP}$ ), the design objective is to minimize the total amount of external lean MSAs, i.e., the unit costs of the process lean MSAs are set to zero, and that of the external ones are set to unity. Because there is no storage tank, the design of networks of any one time period is independent of that of other periods. Figure 7 shows the network structures in the order of time periods. Also shown in Figure 7 are the amounts of mass load $(\mathrm{kg})$ processed in each period, listed in the upper part of the exchangers. As shown in Figure 7, only rich stream $R_{1}$ and lean stream $S_{2}$ exist in the first period (from hour 0 to hour 3 ), so only unit $R_{1}-S_{2}$ is required. Because the first free lean stream $S_{1}$ is available in the second period (from hour 3 to hour 4 ), the unit $R_{1}-S_{1}$ is thus formed to take on most of the load. In the third period, four mass exchangers are needed because the second rich stream $R_{2}$ needs to be processed; however, the great majority of the load is assumed by the first lean stream $S_{1}$. The fourth and fifth periods are analogous to the first and second periods, except that the second rich stream $R_{2}$ is the one to be treated. The structure shown in Figure 7 is rather rational under the consideration of minimizing the total amount of external lean stream. On the ground that $S_{2}$ is more expensive, the rich stream of every time period would first make use of the first lean stream $S_{1}$ to lower the concentration of the rich stream, using the second lean stream $S_{2}$, which is not free, to achieve the target concentration only if the former operation cannot obtain the goal.

Table 3 part a lists the consumption amounts of rich streams $S_{1}$ and $S_{2}$ in each period, $L_{1 p} t_{p}$ and $L_{2 p} t_{p}$, and the amount of $S_{1}$ remains at the end of each period (i.e., upper limit $L_{1 p}^{(\text {up) }} t_{p}$ minus its consumption $L_{1 p} t_{p}$ ). The total amount used for both process and external mass separating agents are also shown. The network structure without storage tanks that Foo et al. ${ }^{18}$ obtained by using pinch analysis is the same as that of ours; our results are also quite close to that computed by Foo et al. ${ }^{18}$ by using pinch analysis. Because of the characteristics of rounding off in pinch analysis, the amount of $S_{2}$ in Foo's study, $44160 \mathrm{~kg}$, is $6 \mathrm{~kg}$ less than that of ours.

It can be found from Table 3 part a that the consumption of $S_{2}$ is concentrated in the first and fifth periods, and a large amount of $S_{1}$ is left unused in the second-fourth periods, the reason for which is that only $S_{2}$ is available in the first period. Therefore, if the abundant remaining $S_{1}$ generated in periods 2-4 can be employed to substitute for the $S_{2}$ in the first and fifth periods, the amount of $S_{2}$ should be lowered significantly. Notice that the very small amounts of $S_{2}$ in periods 2,3 , and 4 are still needed since the target outlet compositions of the rich streams cannot be met by using $S_{1}$ only. To reach the target outlet compositions, the load of the rich streams should be 


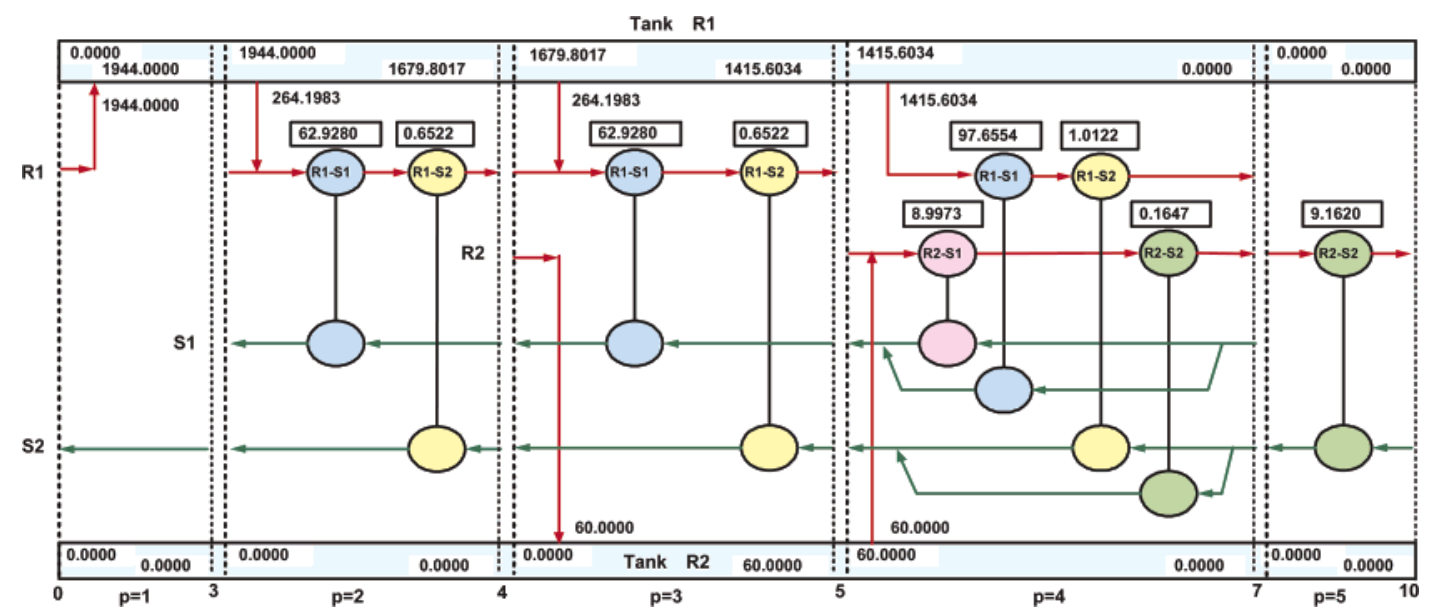

Figure 8. MEN structure of single batch with storage tanks on rich streams by proposed superstructure.

Table 3. Use and Remains of Process and External MSAs under Various Operational Modes

\begin{tabular}{|c|c|c|c|c|c|c|c|}
\hline \multirow{2}{*}{$\begin{array}{l}\text { operational } \\
\text { modes }\end{array}$} & \multirow{2}{*}{$\begin{array}{l}\text { MSA \& } \\
\text { remains }\end{array}$} & \multicolumn{5}{|c|}{ period $\left(t_{p}\right)$} & \multirow[b]{2}{*}{ total $(\mathrm{kg})$} \\
\hline & & $1(3 \mathrm{~h})$ & $2(1 \mathrm{~h})$ & $3(1 \mathrm{~h})$ & $4(2 \mathrm{~h})$ & $5(3 \mathrm{~h})$ & \\
\hline \multirow{3}{*}{$\begin{array}{l}\text { (a) no } \\
\text { tanks } \\
\text { single }\end{array}$} & $L_{1 p} t_{p}$ & & 1470.4697 & 1569.1243 & 197.3092 & & 3236.9032 \\
\hline & remains & & 599.5303 & 500.8757 & 3942.6908 & & 5043.0968 \\
\hline & $L_{2 p} t_{p}$ & 41059.6364 & 140.4000 & 157.0369 & 33.2727 & 2776.3636 & 44166.7096 \\
\hline \multirow{3}{*}{$\begin{array}{l}\text { (b) tanks on } \\
\text { rich str } \\
\text { single }\end{array}$} & $L_{1 p} t_{p}$ & & 2070.0000 & 2070.0000 & 3508.3125 & & 7648.3125 \\
\hline & remains & & 0 & 0 & 631.6875 & & 631.6875 \\
\hline & $L_{2 p} t_{p}$ & 0 & 197.6430 & 197.6430 & 356.6231 & 2776.3636 & 3528.2727 \\
\hline \multirow{3}{*}{$\begin{array}{l}\text { (c) tanks on } \\
\text { rich str } \\
\text { cyclic }\end{array}$} & $L_{1 p} t_{p}$ & & 1939.1882 & 1865.0882 & 4140.0000 & & 7944.2763 \\
\hline & remains & & 130.8118 & 204.9118 & 0 & & 335.7237 \\
\hline & $L_{2 p} t_{p}$ & 0 & 185.1531 & 206.9455 & 409.7196 & 0 & 801.8182 \\
\hline \multirow{4}{*}{$\begin{array}{l}\text { (d) tanks } \\
\text { on } \\
\text { lean str } \\
\text { single }\end{array}$} & $L_{1 p} t_{p}$ & & 1470.4697 & 1569.1243 & 493.2730 & & 3532.867 \\
\hline & $L E_{1 p} t_{p}$ & 0 & 1470.4697 & 1569.1243 & 197.3092 & 295.9638 & 3532.867 \\
\hline & remains & & 599.5303 & 500.8757 & 3646.7270 & & 4747.1330 \\
\hline & $L_{2 p} t_{p}$ & 41059.6364 & 140.4000 & 157.0369 & 33.2727 & 49.9091 & 41439.9551 \\
\hline \multirow{4}{*}{$\begin{array}{l}\text { (e) tanks } \\
\text { on } \\
\text { lean str } \\
\text { cyclic }\end{array}$} & $L_{1 p} t_{p}$ & & 1734.2762 & 2070.0000 & 4140.0000 & & 7944.2762 \\
\hline & $L E_{1 p} t_{p}$ & 4411.4092 & 1470.4697 & 1569.1243 & 197.3092 & 295.9638 & 7944.2762 \\
\hline & remains & & 335.7238 & 0 & 0 & & 335.7238 \\
\hline & $L_{2 p} t_{p}$ & 421.2000 & 140.4000 & 157.0369 & 33.2727 & 49.9091 & 801.8186 \\
\hline
\end{tabular}

eliminated by both $S_{1}$ and $S_{2}$. This aim can be attained by using storage tanks, which will be discussed in the next subsection.

6.2. Single Operation with Storage Tanks on Rich Streams. If a storage tank is attached to every rich stream (i.e., $Z_{i}^{(\text {TankR) }}$ $=1$ for all $i \in \mathrm{RP}, Z_{j}^{(\text {TankS) }}=0$ for all $j \in \mathrm{LP}$ and $Z^{\text {(cyc) }}=0$ ), the network configuration of every time period would be the one shown in Figure 8. There are two tanks in the network, and in every time period, the remaining amount of the tanks in both the starting time and ending time are also shown. When storage tanks are absent, a large amount of $S_{2}$ is consumed; however, a large amount of remaining $S_{1}$ is left intact in periods $2-4$. Therefore, the rich stream of the first period, $R_{1}\left(L_{11} t_{1}=\right.$ $1944 \mathrm{~kg})$, can be reserved until the second period, in which a small amount (264 kg) of the reserved $R_{1}$ is then released and combined with the $R_{1}$ of the second period to make use of the free process lean stream $S_{1}$. Since $S_{1}$ undertakes most of the task, only a small amount of $S_{2}$ is needed to compensate for the shortage. In the third period, the $S_{1}$ available, which is not sufficient to handle all the rich stream, would be used exclusively to take care of the current and reserved $R_{1}$, and therefore, the second rich stream $R_{2}$ would be hoarded up totally, waiting to be processed. All the reserved $R_{1}$ and $R_{2}$ are dealt with in the fourth period. Consequently, in the fifth, the current $R_{2}$ can be handled only by unit $R_{2}-S_{2}$, due largely to the limitation of time and not being able to use a storage tank to lower the consumption of $S_{2}$.
The result of Figure 8 is also revealed in Table 3 part b: the consumption of $S_{2}$ is zero in the first period; the consumption of $S_{1}$ rises in periods $2-4$, and in the meantime, the consumption of $S_{2}$ drops in response, even to zero in periods 2 and 3. This means that $S_{2}$ is displaced by $S_{1}$, which lowers the total consumption of $S_{2}$ to $3528 \mathrm{~kg}$ from the original $44166 \mathrm{~kg}$. The consumption of $S_{1}$ increases in periods $2-4$, the reason for which is that the reserved $R_{1}$ increases the amount of $R_{1}$ that needs to be processed.

In Table 3 part b, there is a common feature in both Foo's and our results: the consumption of $S_{2}$ in the fifth period amounts to $80 \%$ of the total consumption. Accordingly, if we can take advantage of the remaining $S_{1}$ of period 4 to process the $R_{2}$ of period 5, the whole amount of $R_{2}$ can be diminished. This aim, however, cannot be achieved by using single operation, because only rich stream generated in early periods can be withheld and released in later periods to mix with the current lean stream for mass exchange. Fortunately, this problem can be tackled easily by using cyclic operation, as shown in the following subsection.

6.3. Cyclic Operations with Storage Tanks on Rich Streams. The design result of the cyclic operation configuration (i.e., $Z_{i}^{(\text {TankR) }}=Z^{\text {(cyc) }}=1$ for all $i \in \mathrm{RP}$ and $Z_{j}^{(\text {TankS) }}=0$ for all $j \in \mathrm{LP}$ ), is shown in Figure 9. It is clear that, in the first and the fifth periods, all units are not utilized: the rich stream 1 is stored, waiting to be processed in later periods. In the first 


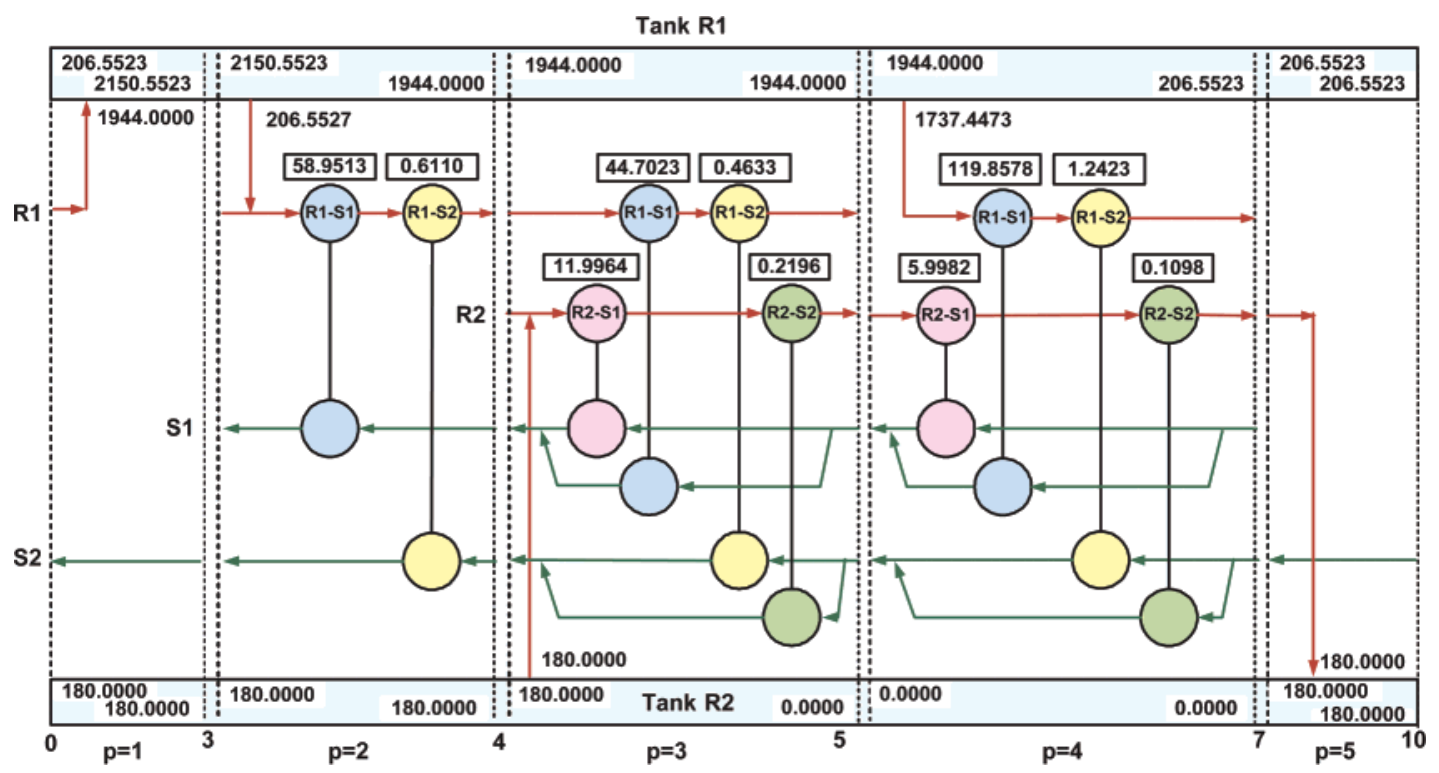

Figure 9. MEN structure of cyclic batch with storage tanks on rich streams by proposed superstructure.

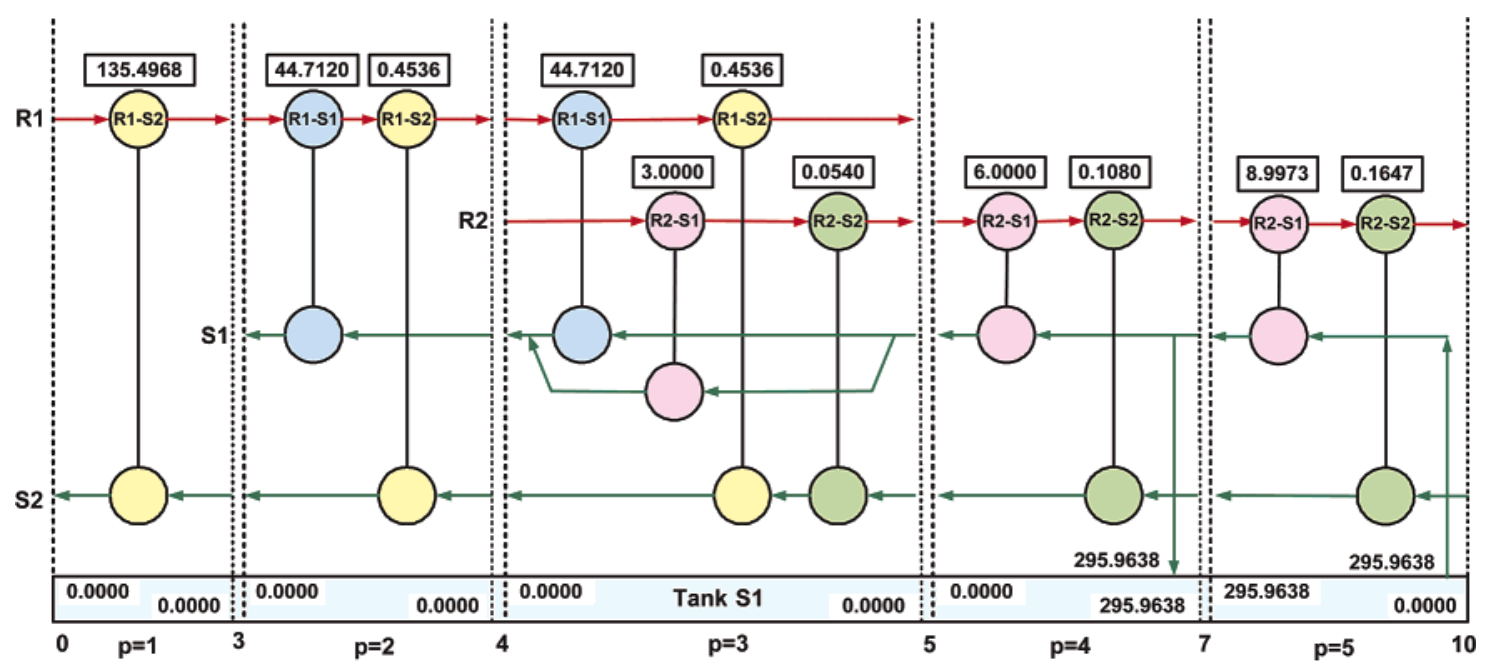

Figure 10. MEN structure of single batch with storage tanks on process lean streams by proposed superstructure.

period, the whole $R_{1}$ flows in, being released in a later period, preventing the first period from using $S_{2}$, which is the same case as that of single operation with storage tanks for rich streams shown in Figure 8. The major discrepancy between cyclic operation and single operation is in the part of $R_{2}$ : the $R_{2}$ in the fifth period of a cyclic operation is withheld totally and is stored in the second storage tank. The temporarily stored $R_{2}$ is then released in the third period of the next cycle to exchange mass with the surplus $S_{1}$. The same effect can also be observed in Table 3 part c. The fifth period does not need to use external $S_{2}$, which lessens the total consumption of $S_{2}$ from $3528 \mathrm{~kg}$ in the single operation further to $801 \mathrm{~kg}$. The temporarily reserved $R_{2}$ in the fifth period is processed later by using $S_{1}$ in period 3 of the next cycle, which causes the total remaining amount of $S_{1}$ to decrease from $631 \mathrm{~kg}$ in the singleoperation case to $336 \mathrm{~kg}$.

6.4. Single Operation with Storage Tanks on Process Lean Streams. Table 3 part d lists the consumption amount of rich streams $S_{1}$ and $S_{2}$ in each period, $L_{1 p} t_{p}$ and $L_{2 p} t_{p}$, the actual amount of rich stream in part of $S_{1}$ exchanged with rich streams, $\mathrm{LE}_{1 p} t_{p}$, and the amount of $S_{1}$ remaining at the end of each period (i.e., upper limit $L_{1 p}^{(\mathrm{up})} t_{p}$ minus its consumption $L_{1 p} t_{p}$ ). The total amount used for both process and external mass separating agents are also shown.
It should be noted that, in the COG process discussed in this paper, since the rich stream, being indeed in a gas state, cannot be stored conveniently, a liquid-state process lean stream can thus be considered to be stored to accomplish the same purpose of lessening the purchase of external MSA. The results of a liquid-type process lean stream storage tank used in single operation and cyclic operation will be elucidated in the next two subsections.

As shown in Figure 10, no free lean stream $S_{1}$ exists in the first period, and consequently, all rich streams $R_{1}$ must be processed by using external lean stream $S_{2}$. Although there is also no free process lean stream available in the fifth period, the superfluous process lean stream $S_{1}$ from the fourth period can be amassed and then used in the fifth period. It is not necessary, therefore, to purchase external lean MSAs to process $R_{2}$ in the fifth period. Comparing parts a and d of Table 3, we can find $296 \mathrm{~kg}$ more $S_{1}$ in the fifth period, all of which comes from the remains in the fourth period by $3942.7-3646.7=$ $296 \mathrm{~kg}$, is used in the fifth period. However, this would not increase the cost but decrease the amount of external $S_{2}$ by $2776.4-49.9=2726.5 \mathrm{~kg}$ in the fifth period. In fact, most of the $S_{2}$ is consumed in the first period, yet a lot of $S_{1}$ is left in the second and third periods, which means that there is plenty 


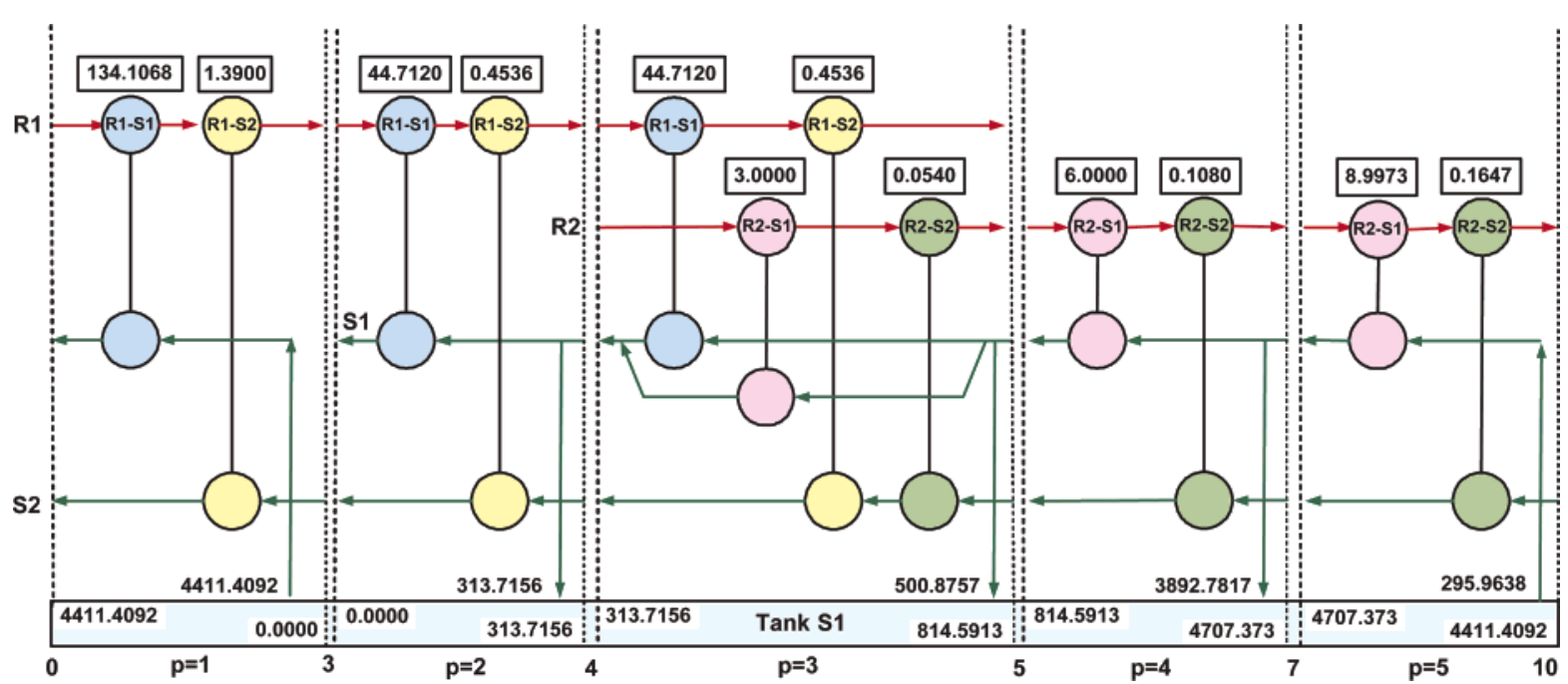

Figure 11. MEN structure of cyclic batch with storage tanks on process lean streams by proposed superstructure.

of room for implementing cyclic operation, as is discussed in the next subsection.

6.5. Cyclic Operation with Storage Tanks on Process Lean Streams. It has been shown that most of the external $S_{2}$ is exhausted in the first period, which lacks process $S_{1}$, and a great deal of free $S_{1}$ is left unused in the second and third periods, so cyclic operation can remedy the situation that free process MSA $\left(S_{1}\right)$ is squandered and that a large sum of money is spent in buying external lean MSA $\left(S_{2}\right)$. The network configuration of the cyclic operation is shown in Figure 11, in which the remains of the free $S_{1}$ of the second, third, and fourth periods are funneled into Tank $\mathrm{S} 1$ for storing. In the fifth period, some preserved $S_{1}$ is discharged to perform mass transfer with $R_{2}$, and the remaining $S_{1}$ is reserved to perform mass transfer with $R_{1}$ in the first period of the next cycle.

It can be discovered, with the comparison of cases e and $d$ of Table 3 , that $41059-421=40638 \mathrm{~kg}$ less external $S_{2}$ is consumed in the first period, which makes the total amount used decrease to $801 \mathrm{~kg}$. The same result also appears in case c; in other words, for recurrent batch or semicontinuous operational processes, the great cost spent in purchasing external lean MSAs can be saved by employing cyclic operation, storing part of the rich streams or free lean MSAs in specific storage tanks. Therefore, the choice of which method depends on the possibility and accessibility of each storing scheme. Besides, although the whole process is of semicontinuous periodic operation, continuous operation mode should be easier to handle for operation of separating units. Accordingly, how to design a proper storing scheme for the semicontinuous periodic operation to achieve the aim of continuous operation for separating units would be an essential topic in the future research.

\section{Conclusion}

The synthesis of mass exchanger networks for semicontinuous processes is studied in this paper. The available inlet streams of a semicontinuous process are time-dependent since they come from other batch plants. A period-dependent stagewise superstructure is presented for modeling the time-dependent mass exchange operations. A mathematical programming approach based on the stagewise superstructure representation of the MENs is adopted for semicontinuous MEN synthesis, where the design problem is formulated as a mixed-integer nonlinear program (MINLP) to minimize the consumption of external lean mass separating agents. The proposed stagewise superstructure can handle multiple transferable components and can also be extended to include storage tanks on the rich streams as well as on process lean streams. The coke oven gases (COGs) problem from the literature is supplied to demonstrate the applicability of the proposed MEN synthesis method for semicontinuous processes.

\section{Acknowledgment}

Financial supports of the Ministry of Economic Affairs and the National Science Council of ROC under Grants 94-EC-17A-09-S1-019 and NSC94-2214-E-002-007 are appreciated. Valuable suggestions from reviewers are also acknowledged.

\section{Nomenclature}

\section{Indices}

$i=$ index for rich process streams and storage tanks

$j=$ index for lean process streams

$k=$ index for superstructure stages, $1, \ldots, N_{\mathrm{S}}$, and composition locations, $1, \ldots, N_{\mathrm{S}}+1$

$p=$ index for time periods, $1, \ldots, N_{\mathrm{P}}$, and time points, $1, \ldots, N_{\mathrm{P}}$ $+1$

$n=$ index for transferable components

Sets

$\mathrm{RP}=\left\{i \mid i\right.$ is a rich process stream, $\left.i=1, \ldots, N_{\mathrm{R}}\right\}$

$\mathrm{LP}=\left\{j \mid j\right.$ is a lean(process) stream or MSA, $\left.j=1, \ldots, N_{\mathrm{L}}\right\}$

$\mathrm{ST}=\left\{k \mid k\right.$ is a stage in the superstructure, $\left.k=1, \ldots, N_{\mathrm{s}}\right\}$

$\mathrm{TC}=\left\{n \mid n\right.$ is a transferable component, $\left.n=1, \ldots, N_{\mathrm{C}}\right\}$

$\mathrm{TP}=\left\{p \mid p\right.$ is a time period, $\left.p=1, \ldots, N_{p}\right\}$

\section{Parameters}

$\mathrm{UC}_{j}=$ cost per kilogram of lean stream $j$

$b_{i j}^{n}=$ intercept of equilibrium line for component $n$ in $i$ rich and $j$ lean match

$G_{i}^{(\mathrm{tot})}=$ total amount of rich stream $i$ during one operation $(\mathrm{kg})$

$G_{i p}=$ mass flow rate of rich stream $i$ at period $p$ should it exists $(\mathrm{kg} / \mathrm{h})$

$L_{j}^{\text {(tot) }}=$ upper bound of total amount of lean stream $j$ during one operation $(\mathrm{kg})$

$L_{j p}^{(\text {up })}=$ upper bound on mass flow rate of lean stream $j$ at period $p(\mathrm{~kg} / \mathrm{h})$

$\bar{M}, \underline{M}=$ upper/lower bounds for mass load in a unit, respectively 
$m_{i j}^{n}=$ slope of equilibrium line for component $n$ in $i$ rich and $j$ lean match

MEU $=$ maximum total number of mass exchange units

$t_{p}=$ elapsed time of period $p(\mathrm{~h})$

$t^{\mathrm{s}}, t^{\mathrm{f}}=$ starting and ending times for a stream (h)

$\Gamma=$ large positive upper bound

$X_{j}^{n(\text { in })}, X_{j}^{n \text { (out) }}, X_{j}^{n \text { (up) }}=$ inlet/outlet/upper compositions of $n$ for lean stream $j$, respectively

$Y_{i}^{n(\text { in) }}, Y_{i}^{n(\text { out })}, Y_{i}^{n(\text { up })}=$ inlet/outlet/upper compositions of $n$ for rich stream $i$, respectively

$Z^{(\mathrm{cyc})} \in\{0,1\}=1$ denotes cyclic operation

$Z_{i}^{\text {(TankR) }}, Z_{j}^{\text {(TankS) }} \in\{0,1\}=1$ denotes existence of storage tank on stream $i$ or $j$

$Z_{i p}^{\text {(rich) }}, Z_{j p}^{(\text {lean })} \in\{0,1\}=1$ denotes existence of stream $i$ or $j$ at period $p$

$\epsilon_{i j}^{n}=$ minimum composition difference of component $n$ between $i$ rich and $j$ lean streams

\section{Positive and Binary Variables}

$d y x i_{i j k p}^{n}, d y x o_{i j k p}^{n}=$ composition approach in the lean/rich end of the mass exchanger between rich $i$ and lean $j$ in stage $k$ at period $p$

$g_{i j k p}=$ mass flow rate of rich $i$ that is connected to lean $j$ in stage $k$ at period $p(\mathrm{~kg} / \mathrm{h})$

$\mathrm{GE}_{i p}=$ mass flow rate of rich stream $i$ flow into first stage at period $p(\mathrm{~kg} / \mathrm{h})$

$\mathrm{GS}_{i p}^{(\mathrm{in})}=$ mass flow rate of rich stream $i$ flow into storage $i$ at period $p(\mathrm{~kg} / \mathrm{h})$

$\mathrm{GS}_{i p}^{\text {(out) }}=$ mass flow rate of storage $i$ flow into rich stream $i$ at period $p(\mathrm{~kg} / \mathrm{h})$

$l_{i j k p}=$ mass flow rate of lean $j$ that is connected to rich $i$ in stage $k$ at period $p(\mathrm{~kg} / \mathrm{h})$

$L_{j p}=$ mass flow rate of lean stream $j$ at period $p(\mathrm{~kg} / \mathrm{h})$

$\mathrm{LE}_{j p}=$ mass flow rate of lean stream $j$ flow into last stage at period $p(\mathrm{~kg} / \mathrm{h})$

$\mathrm{LS}_{j p}^{\text {(in) }}=$ mass flow rate of lean stream $j$ flow into storage $j$ at period $p(\mathrm{~kg} / \mathrm{h})$

$\mathrm{LS}_{j p}^{\text {(out) }}=$ mass flow rate of storage $j$ flow into rich stream $j$ at period $p(\mathrm{~kg} / \mathrm{h})$

$M_{i j k p}^{n}=$ mass load per hour exchanged for component $n$ between rich stream $i$ and lean stream $j$ in stage $k$ at period $p(\mathrm{~kg} / \mathrm{h})$

$Q_{i p}^{\text {(TankR) }}, Q_{j p}^{\text {(TankS) }}=$ existent quantity of storage $i(j)$ at time point $p, p \in\left\{1 \ldots N_{\mathrm{P}}+1\right\}(\mathrm{kg})$

$s x_{i j k p}^{n}, s y_{i j k p}^{n}=$ composition of $n$ for the part of lean $j /$ rich $i$ that is connected to rich $i /$ lean $j$, respectively, in the rich end of an exchanger in stage $k$ at period $p$

$x_{j k p}^{n}, y_{i k p}^{n}=$ composition of $n$ for rich $i /$ lean $j$ match, respectively, at rich end of stage $k$ at period $p$

$z_{i j k} \in\{0,1\}=1$ denotes existence of match $(i, j)$ in stage $k$

$z p_{i j k p} \in\{0,1\}=1$ denotes existence of match $(i, j)$ in stage $k$ at period $p$

$z r_{i p}^{\text {(in) }} \in\{0,1\}=1$ denotes existence of rich stream $i$ flow into storage $i$ at period $p$

$z r_{i p}^{\text {(out) }} \in\{0,1\}=1$ denotes existence of storage $i$ flow into rich stream $i$ at period $p$

$z s_{i p}^{(\text {in })} \in\{0,1\}=1$ denotes existence of lean stream $j$ flow into storage $j$ at period $p$ $z s_{i p}^{\text {(out) }} \in\{0,1\}=1$ denotes existence of storage $j$ flow into rich stream $j$ at period $p$

\section{Literature Cited}

(1) Hallale, N. Mass Transfer Technology for Pollution Prevention. In Process Design Tools for the Environment; Sikdar, S. S., El-Halwagi, M. M., Eds.; Taylor \& Francis: London, 2001; Chapter 7.

(2) El-Halwagi, M. M.; Manousiouthakis, V. Synthesis of mass exchange networks. AIChE J. 1989, 35, 1233.

(3) El-Halwagi, M. M.; Manousiouthakis, V. Automatic synthesis of mass exchange networks with single component targets. Chem. Eng. Sci. 1990, 45, 2813.

(4) El-Halwagi, M. M.; Manousiouthakis, V. Simultaneous synthesis of mass-exchange and regeneration networks. AIChE J. 1990, 36, 1209.

(5) Hallale, N.; Fraser, D. M. Capital and total cost targets for mass exchange networks. Part 1: Simple capital cost models. Comput. Chem. Eng. 2000, 23, 1661

(6) Hallale, N.; Fraser, D. M. Capital and total cost targets for mass exchange networks. Part 2: Detailed capital cost models. Comput. Chem. Eng. 2000, 23, 1681.

(7) Hallale, N.; Fraser, D. M. Supertargeting for mass exchange networks. Part I: Targeting and design techniques. Trans. Inst. Chem. Eng. 2000, 78, 202.

(8) Hallale, N.; Fraser, D. M. Supertargeting for mass exchange networks. Part II: Applications. Trans. Inst. Chem. Eng. 2000, 78, 208.

(9) Chen, C. L.; Hung, P. S. Simultaneous synthesis of mass exchange networks for waste minimization. Comput. Chem. Eng. 2005, 29 (7), 1561.

(10) Chen, C. L.; Hung, P. S. Retrofit of mass-exchange networks with superstructure-based MINLP formulation. Comput. Chem. Eng. 2005, 44 (18), 7189.

(11) Lee, S.; Park, S. Synthesis of mass exchange network using process graph theory. Comput. Chem. Eng. 1996, 20, S201.

(12) Gupta, A.; Manousiouthakis, V. Waste reduction through multicomponent mass exchange network synthesis. Comput. Chem. Eng. 1994, 18, S585.

(13) Bagajewicz, M. J.; Pham, R.; Manousiouthakis, V. On the state space approach to mass/heat exchanger network design. Chem. Eng. Sci. 1998, 53, 2595.

(14) Wilson, S.; Manousiouthakis, V. IDEAS approach to process network synthesis: Application to multicomponent MEN. AIChE J. 2000, $46,2408$.

(15) Garrard, A.; Fraga, E. S. Mass exchange network synthesis using genetic algorithms. Comput. Chem. Eng. 1998, 22, 1837.

(16) Papalexandri, K. P.; Pistikopoulos, E. N.; Floudas, C. A. 1994. Mass exchange networks for waste minimization: A simultaneous approach. Trans. Inst. Chem. Eng. 1994, 72A, 279.

(17) Wang, Y. P.; Smith, R. Time pinch analysis. Trans. Inst. Chem. Eng. 1995, 73A, 905.

(18) Foo, C. Y.; Manan, Z. A.; Yunus, R. M.; Aziz, R. A. Synthesis of mass exchange network for batch processes-Part I: Utility targeting. Chem. Eng. Sci. 2004, 59 (5), 1009.

(19) Foo, C. Y.; Manan, Z. A.; Yunus, R. M.; Aziz, R. A. Synthesis of mass exchange network for batch processes-Part II: Minimum units target and batch network design. Chem. Eng. Sci. 2005, 60 (5), 1349.

(20) Foo, C. Y.; Manan, Z. A.; Tan Y. L. Synthesis of maximum water recovery network for batch process systems. J. Cleaner Prod. 2005, 1315, 1381.

(21) Yee, T. F.; Grossmann, I. E. Simultaneous optimization models for heat integration-I. Area and energy targeting and modeling of multistream exchangers. Comput. Chem. Eng. 1990, 14, 1151.

(22) Yee, T. F.; Grossmann, I. E. Simultaneous optimization models for heat integration-II. Heat exchanger network synthesis. Comput. Chem. Eng. 1990, 14, 1165.

(23) Astarita, G.; Savage, D. W.; Bisto, A. Gas Treating with Chemical Solvents; Wiley: New York, 1983.

(24) Brooke, A.; Kendrick, D.; Meeraus, A.; Raman, R.; Rosenthal, R. E. GMAS: A User's Guide; Scientific Press: Redwood City, CA, 2003.

Received for review February 22, 2006 Revised manuscript received July 19, 2006 Accepted July 20, 2006

IE0602207 